\title{
Squamous Papilloma: Case Report and Review of Literature
}

\author{
Prashant P. Jaju ${ }^{1 *}$, Prashant V. Suvarna ${ }^{2}$, Rajiv S. Desai ${ }^{3}$ \\ ${ }^{1}$ Department of Oral Medicine, Diagnosis and Radiology, MGV's KBH Dental College \& Hospital, Nashik, Maharashtra, India \\ ${ }^{2}$ Department of Oral Medicine and Radiology, Dr. D. Y. Patil Dental College and Hospital, Mahesh Nagar, Pimpri, India \\ ${ }^{3}$ Department of Oral Maxillofacial Pathology, Dr. D. Y. Patil Dental College and Hospital, Mahesh Nagar, Pimpri, India
}

\begin{abstract}
Squamous papillomas are common lesions of the oral mucosa with a predilection for the mucosa of the hard and soft palate. As an oral lesion, it raises concern because of its clinical appearance, which may mimic exophytic carcinoma, verrucous carcinoma or condyloma acuminatum. Its patho-
\end{abstract}

genesis is related to human papilloma virus but there is controversy regarding its viral origin. We present a case of squamous papilloma presenting as oral lesion along with a review of the literature.

Keywords squamous papilloma, human papilloma virus, HIV, condyloma acuminatum, koilocytic cell, interferon

Received Dec. 27, 2009; Revision accepted Jun. 22, 2010

\section{Introduction}

Squamous papillomas are common lesions of the oral mucosa with a predilection for the mucosa of the hard and soft palate including the uvula and the vermillion of the lips. It is an innocuous lesion that is neither transmissible nor threatening. As an oral lesion, it raises concern because of its clinical appearance, which may mimic exophytic carcinoma, verrucous carcinoma or condyloma acuminatum. Many considered its pathogenesis as being from the human papillomavirus (HPV). But recent literature suggests that presence of HPV may be merely an incidental finding unrelated to the development of a squamous papilloma (Marx and Diane, 2003). We present a case of squamous papilloma in the form of oral lesions, along with a review of the literature.

\section{Case Report}

A 25-year-old married muslim female reported to the department of Oral Medicine of Dr. DY Patil Dental College \& Hospital, Pimpri, Pune with a chief complaint of growth on the palate for six months. History regarding the growth revealed that it was first seen six months prior as a slow-growing non-tender papule. The present lesion was exophytic and sessile in nature, pinkish in colour with pebbled surface, soft in consistency, $2 \mathrm{~cm} \times 2 \mathrm{~cm}$ in size, and situated on palatal rugae area. Another small papule with a pebbled surface, with a size of $1 \mathrm{~cm} \times 1 \mathrm{~cm}$, was seen posterior to the larger lesion (Figure 1). A similar papule was seen on flexor surface of arm of both hands. The index finger of the left hand showed verrucous growth with a dry rough surface which was firm in consistency (Figure 2). The patient elaborated about the lesion on her finger, which appeared before the oral lesion and hence auto-innoculation in the oral cavity was possible. Past medical, dental and personal history was non-contributory. The left submandibular lymph nodes were palpable and tender. Provisional diagnosis of the oral wart was made and the patient was advised special investigation of ELISA. The ELISA test was negative. Surgical excision of the lesion was performed with a $1 \mathrm{~mm}$ margin to the depth of the submucosa. The histopathological diagnosis of squamous papilloma was made at $10 \times$ magnification under $\mathrm{H} \& \mathrm{E}$ staining (Figure 3). A 
one-year follow-up was performed, and there was no evidence of recurrence of the lesion.

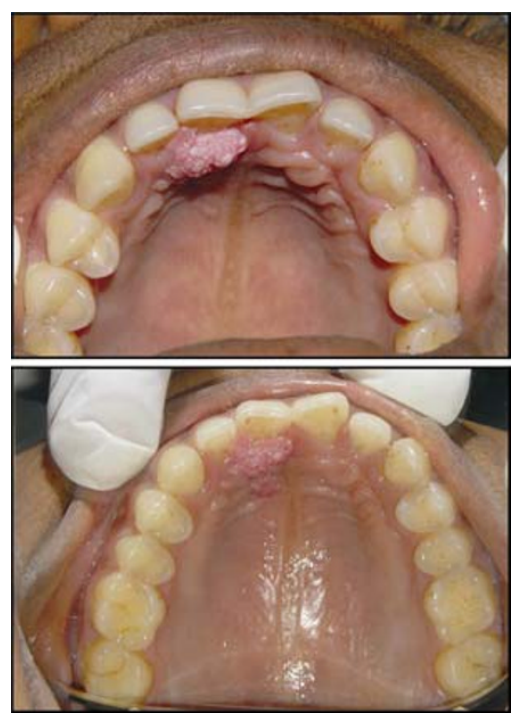

Figure 1 Intra oral view of the lesion present on anterior part of hard palate

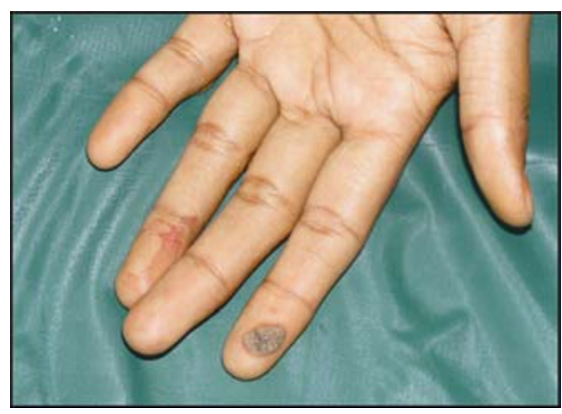

Figure 2 Lesion seen on the finger

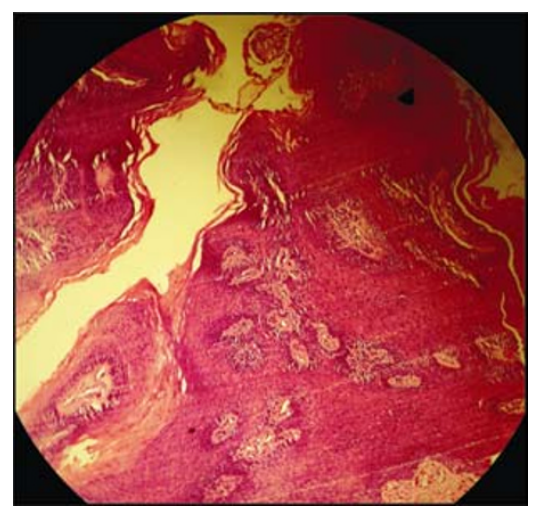

Figure 3 Histopathological picture showing confirmation of squamous papilloma

\section{Discussion}

Oral squamous papilloma is a generic term that is used to include papillary and verrucous growths composed of benign epithelium and minor amounts of supporting connective tissue. The squamous papilloma is associated with human papilloma virus (HPV) types 6, and 11 (Major et al., 2005). Oral squamous papilloma, including the vermilion portion of the lip, is the most common papillary lesion of the oral mucosa and makes up approximately $2.5 \%$ of all oral lesions. Whether all intraoral squamous papillomas are related etiologically to classic cutaneous verruca vulgaris (warts) is unknown. This tumor is of low virulence; i.e, it is not contagious. However, some authors speculate that this condition might actually be a reaction of the tissue to injury rather than a true neoplasia (Harries et al., 1995). In recent years, a clear connection has been established between human papillomavirus (HPV) and the development of squamous papilloma (Crissman et al., 1988; Briskin and Kerner, 1994). The primary means of HPV transmission to children is the ingestion of viral particles of infected cells from the birth canal, whereas in adults HPV is mainly transmitted through sexual contact.

\section{Clinical Features}

Oral squamous papillomas may be found on the vermilion portion of the lips and any intraoral mucosal site, with a predilection for the hard and soft palate and the uvula (Abbey et al., 1980). The latter three sites account for approximately one third of all lesions. In our case, the lesion is seen on anterior region of hard palate. The lesions generally measure less than $1 \mathrm{~cm}$ in range and appear as pink-to-white exophytic granular or cauliflowerlike surface alterations. The lesions are generally asymptomatic as was in the present case. Squamous papillomas are traditionally divided into two types: isolated-solitary and multiple-recurring. The former is usually found in an adult's oral cavity, while the latter is mostly found in a child's laryngotracheobronchial complex. The isolated-solitary lesions are exophytic, pedunculated growths that resemble a cauliflower in appearance. They are usually white, but can occasionally be pink. Patients who are HIV-positiveoften have multiple oral lesions. Malignant transformation of a papilloma is more common in the multiple-recurring type. Dos 
Reis et al. reported a case in which squamous papilloma lesions occurred concurrently in the oral cavity and genital area (Dos Reis et al., 2009).

\section{Histological Features}

Many long, thin, and finger-like projections extend above the surface of mucosa. Each fingerlike projection is lined by stratified squamous epithelium and contains a thin central connective tissue. The spinous cells proliferate in a papillary pattern. Koilocytes-HPV altered cells may or may not be seen. Upper-level epithelial cells demonstrate nuclei that are pyknotic and crenated, often surrounded by an edematous or optically-clear zone, forming the so-called "koilocytic" cell. This cell is thought to be indicative of a virally-altered state. Chronic inflammatory cells are also seen.

\section{Role of Human Papilloma Virus}

Oral squamous papillomas have been shown to be associated with the same human papillomavirus (HPV) subtype that causes cutaneous warts. Other oral papillomas have been associated with different HPV subtypes. Whether all oral papillomas are of viral origin is also open to question. It has been shown that the class of HPVs is very large (more than 100 subtypes) and that individually these viruses are associated with many conditions of squamous epithelium (Table 1). HPV is a member of the papovavirus group. It is a DNA virus containing a single molecule of double-stranded DNA. The viruses themselves are nonenveloped icosahedral particles ranging from $45 \mathrm{~nm}$ to $55 \mathrm{~nm}$ in diameter with 72 capsomeres in a skewed arrangement. Various species are antigenically distinct, sharing some common antigenic determinants. Replication of HPV occurs within the nuclei of epithelial cells as a result of stimulation of host DNA synthesis. The viral genome is expressed in both early and late stages, with the host histone proteins being incorporated into the virions. If progeny production is blocked, persistent infection may result. However, if intact viruses are produced, new infective particles can be released with or without cell death (Zeuss et al., 1991; Regezi et al.,
2003).

Table 1 Lesion caused by human papillomavirus

\begin{tabular}{ll}
\hline \multicolumn{1}{c}{ Lesion } & \multicolumn{1}{c}{$\begin{array}{c}\text { Type of human } \\
\text { papillomavirus involved }\end{array}$} \\
\hline Oral papilloma/wart & $2,6,11,57$ \\
Focal epithelial hyperplasia & 13,32 \\
Dysplastic wart (HIV) & 16,18 \\
Flat wart & 3,10 \\
Verrucous carcinoma & 16,18 \\
Condyloma acuminatum & 6,11 \\
Verruca vulgaris, skin & $2,4,40$ \\
Laryngeal papilloma & 11 \\
Conjunctival papilloma & 11 \\
\hline
\end{tabular}

\section{Differential Diagnosis}

The differential diagnosis of oral squamous papilloma, when solitary, includes verruciform xanthoma, papillary hyperplasia, and condyloma acuminatum. Verruciform xanthoma may resemble squamous papilloma, although this lesion has a distinct predilection for the gingiva and the alveolar ridge. A cause-and-effect relationship (e.g., lesion appearing under an ill-fitting denture) should be evident for inflammatory papillary hyperplasia. The condyloma would be larger than the papilloma, would have a broader base, and would appear pink-to-red as a result of less keratinization. In addition clustered or multiple squamous papillomas would suggest focal epithelial hyperplasia (Heck disease) (Marx and Diane, 2003; Regezi et al., 2003).

\section{Treatment and Prognosis}

Although many oral squamous papillomas appear to be virally induced, the infectivity of the HPV must be of a very low order. The route of transmission of the virus is unknown for oral lesions, although direct contact would be favoured as in the present case. Surgical removal is the treatment of choice by either routine excision or laser ablation. Other treatment modalities include electrocautery, cryosurgery, and intralesional injections of inter- 
feron. Recurrence is uncommon, except for lesions in patients infected with human immunodeficiency virus (HIV) (Carneiro T et al., 2009).

\section{References}

Robert EM, Diane S (2003). Oral and maxillofacial pathology: A rationale for diagnosis and treatment. New Malden: Qunitessence publishing Co, pp261-262.

Major T, Szarka K, Sziklai I, Gergely L, Czegledy J(2005). The characteristics of human papillomavirus DNA in head and neck cancers and papillomas. J Clin Pathol, 58(1): 51-55.

Harries ML, Juman S, Bailey CM (1995). Recurrent respiratory papillomatosis in the larynx: re-emergence of clinical disease following surgery. Int J Pediatr Otorhinolaryngol, 31(2/3): 259-262.

Crissman JD, Kessis T, Shah KV, Fu YS, Stoler MH, Zarbo RJ, et al. (1988). Squamous papillary neoplasia of the adult upper aerodigestive tract. Hum Pathol, 19(12): 1387-1396.

Briskin KB, Kerner MM, Calcaterra TC (1994). Squamous papillomas of the nasopharynx treated by a uvulo- palatopharyngoplasty approach. Am J Otolaryngol, 15: 379-382.

Abbey LM, Page DG, Sawyer DR (1980). The clinical and histopathologic features of a series of 464 oral squamous cell papillomas. Oral Surg Oral Med Oral Pathol, 49(5): 419-428.

Dos Reis HB, Rabelo PC, De Santana MF, Ferreira DC, Filho AC (2009). Oral squamous papilloma and condyloma acuminatum as manifestations of buccal-genital infection by human papillomavirus. Indian J Sex Transm Dis, 30: 40-42.

Zeuss M, Miller C, White D (1991). In situ hybridization analysis of human papilloma virus DNA in oral mucosal lesions. Oral Surg Oral Med Oral Pathol, 71: 714-720.

Regezi J, Scuibba J, Jordan R (2003). Oral pathology: Clinical pathological correlations. 4th Eds. Philadelphia: Saunders, pp143-145.

Carneiro T, Marinho SA, Verli FD, Mesquita ATM, Lima NL, Miranda JL (2009). Oral squamous papilloma: clinical, histologic and immunohistochemical analyses. J Oral Sci, 51(3): 367-372.

*Corresponding author: Prashant P. Jaju

Address: Department of Oral Medicine, Diagnosis and Radiology, MGV's KBH Dental College \& Hospital, Nashik, Maharashtra, India

Tel: $919890183750 \quad$ E-mail: docprashant_jaju@yahoo.com 